\title{
ChemComm
}

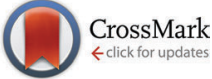

Cite this: Chem. Commun., 2016, 52,11382

Received 20th May 2016,

Accepted 19th August 2016

DOI: $10.1039 / c 6 c c 04275 a$

www.rsc.org/chemcomm

\section{A polarized liquid-liquid interface meets visible light-driven catalytic water oxidation $\dagger$}

\author{
Shokoufeh Rastgar, ${ }^{a b}$ Martin Pilarski ${ }^{a}$ and Gunther Wittstock*a
}

\begin{abstract}
Hyperbranched nanostructured bismuth vanadate at a chemically polarized water/organic interface is applied for efficient visible lightdriven catalytic oxidation of water in the presence of $\left[\mathrm{Co}(\mathrm{bpy})_{3}\right]\left(\mathrm{PF}_{6}\right)_{3}$ as an organic soluble electron acceptor. The photocurrent response originating from the transfer of photo-excited electrons in $\mathrm{BiVO}_{4}$ to $\left[\mathrm{Co}(\mathrm{bpy})_{3}\right]^{3+}$ is measured by scanning electrochemical microscopy.
\end{abstract}

Inspired by biological photosynthesis, the current research aims at converting sunlight to chemical fuels by driving energetically uphill chemical reactions yielding energy-rich compounds. Conceptually this represents an approach for solving the energy challenge with minimal environmental impact. ${ }^{1-4}$ Liquid/liquid (L/L) interfaces, or, more precisely, interfaces between two immiscible electrolyte solutions (ITIES), have been proposed as simple models mimicking important functions of biomembranes at which the process of photosynthesis proceeds in green plants. The analogy extends to charge carrier separation by two interacting photocenters (equivalent to a z-scheme) and catalyst regeneration at interfaces. ${ }^{5}$ ITIES can be polarized either externally using a potentiostat or chemically by changing the composition or concentration of supporting electrolytes in the organic or aqueous phase. The applied galvanic potential difference across the interface could control the efficiency and pathway of interfacial processes involving charged reactants. ${ }^{6-8}$ Hence, the design of efficient artificial photosynthesis systems based on charge transfer at ITIES has recently received significant attention. ${ }^{9-11}$ Such systems utilize sunlight to split water into molecular oxygen $\mathrm{O}_{2}$ and hydrogen $\mathrm{H}_{2}$ (as renewable solar fuels). ${ }^{11}$ The water oxidation reaction (WOR), a multi-electron multi-proton transfer, is energy demanding and considered as the most challenging step in water splitting. It requires suitable catalytic conditions for reasonable rates and/or overpotentials. ${ }^{12}$

\footnotetext{
${ }^{a}$ Institute of Chemistry, Carl von Ossietzky University of Oldenburg, D-26111 Oldenburg, Germany.E-mail: gunther.wittstock@uni-oldenburg.de; Fax: +49441798 3979; Tel: +49 4417983971

${ }^{b}$ Hanse-Wissenschaftskolleg, Lehmkuhlenbusch 4, D-27753 Delmenhorst, Germany. Fax: +4942219160 199; Tel: +4942219160100

$\dagger$ Electronic supplementary information (ESI) available. See DOI: 10.1039/c6cc04275a
}

Bismuth vanadate $\left(\mathrm{BiVO}_{4}\right)$ is one of the most interesting visible-light-driven photocatalysts for water oxidation, because it has a suitable position of the valence band (VB) edge at $c a$. $2.4 \mathrm{eV} v s$. RHE, a sufficiently narrow bandgap for visible light absorption, is stable, abundant and of low cost. However, it suffers from poor charge transport properties causing excessive electron-hole recombination. ${ }^{13-17}$ Furthermore, the hole transfer kinetics for WOR is sluggish. ${ }^{14}$ One direction for further improvement is size and shape control in order to facilitate the collection and separation of electron-hole pairs at the semiconductor/ solution interfaces. ${ }^{14}$

Our approach herein is the use of hyperbranched $\mathrm{BiVO}_{4}$ at a chemically polarized ITIES ${ }^{18}$ for enhancing the rate of photocatalytic WOR (Fig. 1). The nanoscale branches minimize the charge carrier diffusion length to the interface where they are converted before recombining. This is further supported by $\left[\mathrm{Co}(\mathrm{bpy})_{3}\right]\left(\mathrm{PF}_{6}\right)_{3}$ as an electron-acceptor in the organic phase. By efficient relaying of the photo-excited electrons from $\mathrm{BiVO}_{4}$ to the electron acceptor the electron/hole pair separation is facilitated after photoexcitation in $\mathrm{BiVO}_{4}$. This function is analogous to that of the electron transport chain between photosystems I and II. $^{1}$ Interestingly, the driving force for electron transfer to $\left[\mathrm{Co}(\mathrm{bpy})_{3}\right]^{3+}$ can be controlled easily by changing the polarization of the ITIES, which then clearly influences the efficiency of electron transfer from water to photogenerated holes (yielding $\mathrm{O}_{2}$ ).

In the present work, the interfacial photo-induced electron transfer (ET) reaction is studied by means of scanning electrochemical microscopy (SECM), which has quickly become an important tool for probing rapid processes at ITIES, including ET, ${ }^{19-22}$ ion transfer, ${ }^{23-26}$ and molecular $\operatorname{transfer}^{27}$ with high sensitivity. SECM is used here for recording the scavenging of photoelectrons by reduction of $\left[\mathrm{Co}(\mathrm{bpy})_{3}\right]^{3+}$ at the $\mathrm{BiVO}_{4} /$ butyronitrile interface. The SECM microelectrode (ME) oxidizes the resulting $\left[\mathrm{Co}(\mathrm{bpy})_{3}\right]^{2+}$. Finally, WOR by photo-generated holes of $\mathrm{BiVO}_{4}$ at the chemically polarized ITIES is followed by online detection of $\mathrm{O}_{2}$ while the cell is irradiated using visible light $(\lambda>420 \mathrm{~nm})$. 
A)
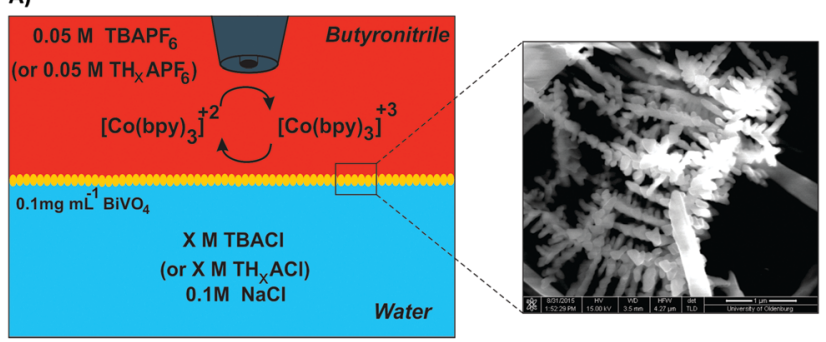

B)

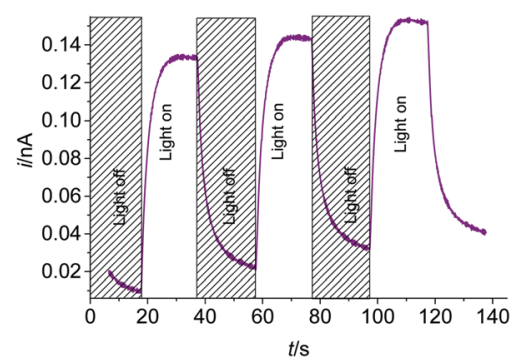

Fig. 1 (A) Schematic representation of the initial composition of the aqueous and organic phases for chemical polarization of the $L / L$ interface used for the study of $\mathrm{BiVO}_{4}$ photoactivity. Magnified SEM image of the hyperbranched structure of $\mathrm{BiVO}_{4}$; $(\mathrm{B})$ typical photocurrent transient for the detection of $\left[\mathrm{Co}(\mathrm{bpy})_{3}\right]^{2+}$ recorded at a Au ME $\left(r_{\mathrm{T}}=12.5 \mu \mathrm{m}, d=20 \mu \mathrm{m}\right)$ with an applied potential of $E_{\mathrm{T}}=0.5 \mathrm{~V}$ (vs. Ag quasi-reference electrode $(\mathrm{AgQRE}))$. The butyronitrile phase contained $0.5 \mathrm{mM}\left[\mathrm{Co}(\mathrm{bpy})_{3}\right]\left(\mathrm{PF}_{6}\right)_{3}$ and $0.05 \mathrm{M} \mathrm{TBAPF}_{6}$, and the aqueous phase contained $0.1 \mathrm{M} \mathrm{NaCl}$ and $0.01 \mathrm{M} \mathrm{TBACl}$.

The composition of the cell with the ITIES is schematically shown in Fig. 1A. Tetrabutylammonium chloride (TBACl) and tetrabutylammonium hexafluorophosphate $\left(\mathrm{TBAPF}_{6}\right)$ are the supporting electrolytes in water and butyronitrile phases, respectively. Tetrabutylammonium $\left(\mathrm{TBA}^{+}\right)$is highly hydrophobic and acts as a common ion which induces the specific potential difference across the interface according to the Nernst-Donnan equation. ${ }^{22,28}$

The $\mathrm{BiVO}_{4}$ nanocrystals are initially well-dispersed in the aqueous phase. The ITIES polarized immediately by ion-transfer and then $\mathrm{BiVO}_{4}$ nanocrystals are driven electrostatically to the interface. The synthesized $\mathrm{BiVO}_{4}$ nanocrystals resemble the shape of trunks with nano-scaled branches (so-called hyper-branched structure). Detailed data on the synthesis and characterization of $\mathrm{BiVO}_{4}$ and $\left[\mathrm{Co}(\mathrm{bpy})_{3}\right]^{2+/ 3+}$ are provided in the ESI. $\dagger$

Photoinduced ET from nanocrystalline $\mathrm{BiVO}_{4}$ to $\left[\mathrm{Co}(\mathrm{bpy})_{3}\right]^{3+}$ is investigated using SCEM. A Au ME with radius $r_{\mathrm{T}}=12.5 \mu \mathrm{m}$ is placed in the upper, organic phase at a distance $d=20 \mu \mathrm{m}$ to the ITIES at a potential $E_{\mathrm{T}}$ of $+0.5 \mathrm{~V}$ ( $v s$. Ag quasi-reference electrode (AgQRE)) to detect sensitively $\left[\mathrm{Co}(\mathrm{bpy})_{3}\right]^{2+}$ formed by the photoinduced ET from $\mathrm{BiVO}_{4}$ to $\left[\mathrm{Co}(\mathrm{bpy})_{3}\right]^{3+}$ before it is diluted in the bulk of the organic phase. The $\mathrm{Au} \mathrm{ME}$ is approached by monitoring the hindered diffusion of $\left[\mathrm{Co}(\mathrm{bpy})_{3}\right]^{3+}$ in the organic phase. The transient $\left[\mathrm{Co}(\mathrm{bpy})_{3}\right]^{2+}$ oxidation current at the Au ME is shown in Fig. 1B. No photoresponses are detected if either $\mathrm{BiVO}_{4},\left[\mathrm{Co}(\mathrm{bpy})_{3}\right]^{3+}$ or illumination is absent (data not shown).
Clearly, band-gap illumination of the interface leads to interfacial ET to $\left[\mathrm{Co}(\mathrm{bpy})_{3}\right]^{3+}$ in the organic phase. The generated photo-induced electron-hole pairs with quasi-Fermi levels approach the energies of the conduction band (CB) and valence band (VB) of $\mathrm{BiVO}_{4}$. The CB energy of $\mathrm{BiVO}_{4}$ is $+0.02 \mathrm{~V}^{29}$ and the redox potential of $\left[\mathrm{Co}(\mathrm{bpy})_{3}\right]^{3+}$ in butyronitrile is $+0.34 \mathrm{~V}$ vs. RHE. Therefore, heterogeneous ET of CB electrons from $\mathrm{BiVO}_{4}$ to $\left[\mathrm{Co}(\mathrm{bpy})_{3}\right]^{3+}$ appears thermodynamically feasible.

The driving force of the interfacial photo-induced ET reaction is determined by this thermodynamic energy difference and the galvanic potential difference $\left(\Delta_{\mathrm{ao}}^{\mathrm{org}} \phi\right)$ across the ITIES. ${ }^{30,31}$ The influence of $\Delta_{\mathrm{ao}}^{\mathrm{org}} \phi$ is investigated by adjusting it by means of the concentration ratio of $\mathrm{TBA}^{+}$between the aqueous and organic phases. Cyclic voltammograms $(\mathrm{CVs})$ of $\left[\mathrm{Co}(\mathrm{bpy})_{3}\right]^{3+}$ reduction were recorded in the butyronitrile solution as part of a biphasic system containing $0.01-0.1 \mathrm{M} \mathrm{TBA}^{+}$in the aqueous phase and a fixed concentration of $0.05 \mathrm{M} \mathrm{TBA}^{+}$in the organic phase. As shown in the inset of Fig. 2, the reduction potential of $\left[\mathrm{Co}(\mathrm{bpy})_{3}\right]^{3+}$ shifts positively by nearly $60 \mathrm{mV}$ per concentration decade of $\mathrm{TBA}^{+}$, in good agreement with the Nernst-Donnan equation. Please note that the electroneutrality of the two phases is maintained by insertion of the hydrophobic, potentialdetermining ion $\mathrm{TBA}^{+}$into the organic phase. In addition, the influence of $\Delta_{\mathrm{ao}}^{\text {org }} \phi$ is observed clearly by photocurrent responses at the $\mathrm{Au} \mathrm{ME}$ which grows with the $\mathrm{TBA}^{+}$concentration in the aqueous phase (Fig. 2). This causes a more positive potential across the interface contributing to a higher driving force for photo-induced ET.

Interestingly, changing the aqueous electrolyte from acidic to alkaline media dramatically influences the photocurrent responses. As depicted in Fig. 3, the transient signal increases significantly in neutral ( $\mathrm{pH} \mathrm{7,0.1} \mathrm{M} \mathrm{NaCl)} \mathrm{or} \mathrm{alkaline}(\mathrm{pH} 9$, $0.01 \mathrm{mM} \mathrm{NaOH}$ ) aqueous electrolytes compared to the acidic

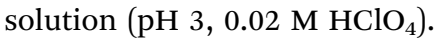

It is known that the energy levels of the $\mathrm{CB}$ and $\mathrm{VB}$ of the $\mathrm{BiVO}_{4}$ semiconductor shift with $\mathrm{pH}$, whereas the redox potential of $\left[\mathrm{Co}(\mathrm{bpy})_{3}\right]^{3+/ 2+}$ is independent of $\mathrm{pH}^{32} \mathrm{~A}$ higher $\mathrm{pH}$ of the reactant solution yields a negative shift of the band-levels of

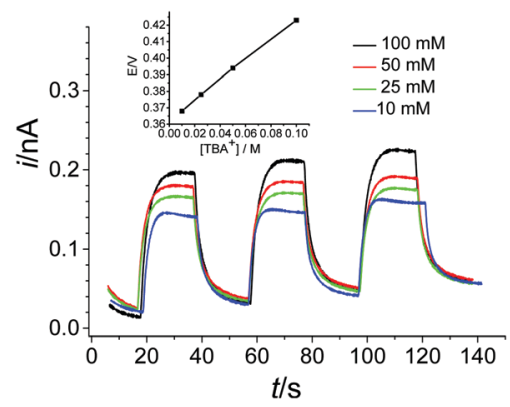

Fig. 2 Photocurrent transients for the detection of $\left[\mathrm{Co}(\mathrm{bpy})_{3}\right]^{2+}$ in butyronitrile at $\mathrm{Au} \operatorname{ME}\left(r_{\mathrm{T}}=12.5 \mu \mathrm{m}, E_{\mathrm{T}}=+0.5 \mathrm{~V}\right.$ (vs. AgQRE)) with different concentrations of $\mathrm{TBACl}$ in the aqueous phase. The butyronitrile solution contained $0.5 \mathrm{mM}\left[\mathrm{Co}(\mathrm{bpy})_{3}\right]\left(\mathrm{PF}_{6}\right)_{3}$ and $0.05 \mathrm{M} \mathrm{TBAPF}_{6}$. From bottom to top, the aqueous solution contained $0.01,0.025,0.05$, and $0.1 \mathrm{M} \mathrm{TBACl}$. The inset figure is the dependence of the half-wave potential $\left(E_{1 / 2}\right)$ on $\mathrm{TBA}^{+}$concentration. 


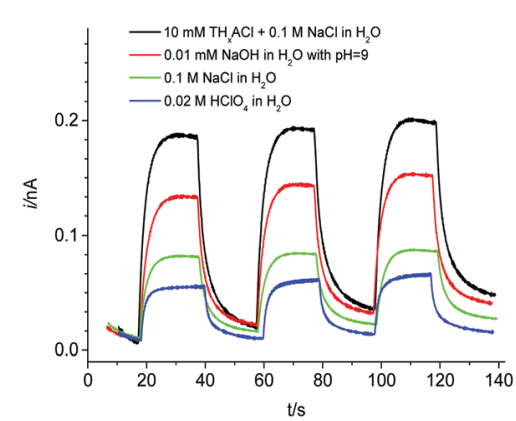

Fig. 3 Photocurrent transients for the detection of $\left[\mathrm{Co}(\mathrm{bpy})_{3}\right]^{2+}$ in butyronitrile at a $\mathrm{Au} \operatorname{ME}\left(r_{\mathrm{T}}=12.5 \mu \mathrm{m}, E_{\mathrm{T}}=+0.5 \mathrm{~V}\right.$ (vs. AgQRE)) with different aqueous supporting electrolytes. The butyronitrile solution contained $0.5 \mathrm{mM}\left[\mathrm{Co}(\mathrm{bpy})_{3}\right]\left(\mathrm{PF}_{6}\right)_{3}$ and $0.05 \mathrm{M} \mathrm{TBAPF}_{6}$. The aqueous solution contained $0.1 \mathrm{M} \mathrm{NaCl}$ and additionally from bottom to top, $0.02 \mathrm{M} \mathrm{HClO}_{4}$, no addition, $0.01 \mathrm{mM} \mathrm{NaOH}$ and $0.01 \mathrm{M} \mathrm{TH}_{x} \mathrm{ACl}$.

$\mathrm{BiVO}_{4}$ (on the electrochemical scale). Consequently, the CB electrons in $\mathrm{BiVO}_{4}$ attain more reductive power towards the approximately $\mathrm{pH}$-independent formal potential of $\left[\mathrm{Co}(\mathrm{bpy})_{3}\right]^{3+}$ and the photo-induced ET proceeds more easily (Fig. 3). Furthermore, the photocurrent signal is enhanced when using tetrahexylammonium $\left(\mathrm{TH}_{x} \mathrm{~A}^{+}\right)$instead of $\mathrm{TBA}^{+}$as the common ion because the more hydrophobic $\mathrm{TH}_{x} \mathrm{~A}^{+}$has a higher tendency to transfer to the organic phase and, therefore, contributes to a higher driving force for the photo-induced ET reaction from $\mathrm{BiVO}_{4}$ to $\left[\mathrm{Co}(\mathrm{bpy})_{3}\right]^{3+}$. $^{18}$

Parallel to the ET reaction between photo-excited electrons of $\mathrm{BiVO}_{4}$ and $\left[\mathrm{Co}(\mathrm{bpy})_{3}\right]^{3+}$, photo-generated holes in the $\mathrm{VB}$ of $\mathrm{BiVO}_{4}$ cause the WOR which is energetically possible. The reaction product, $\mathrm{O}_{2}$, can be detected by online mass spectrometry (ESI-6, ESI $\dagger$ ) as the main product of photooxidation of water. Table 1 summarizes the $\mathrm{O}_{2}$ evolution rates per gram catalyst within the first $10 \mathrm{~min}$ of irradiation. The $\mathrm{O}_{2}$ evolution rate is improved drastically under polarization of the ITIES with $\mathrm{TBA}^{+}$compared to batches without either potential-determining common ions or $\left[\mathrm{Co}(\mathrm{bpy})_{3}\right]\left(\mathrm{PF}_{6}\right)_{3}$ as an electron acceptor in the organic phase. By trapping the photo-excited electrons, the Co complex facilitates both charge separation in $\mathrm{BiVO}_{4}$ and efficient $\mathrm{O}_{2}$ production at the $\mathrm{BiVO}_{4} /$ water interface. Furthermore, the increased

Table 1 Oxygen evolution rate in a batch reactor depending on additions of common ion and electron acceptor

\begin{tabular}{llll}
\hline Batch $^{a}$ & {$\left[\mathrm{Salt}_{\mathrm{aq}}{ }^{b}\right.$} & {$\left[\mathrm{Co}(\mathrm{bpy})_{3}{ }^{3+}\right]_{\text {org }}{ }^{c}$} & $\begin{array}{l}\mathrm{O}_{2} \text { evolution rate } \\
\left(\mu \mathrm{mol} \mathrm{h}^{-1} \mathrm{~g}^{-1}\right)\end{array}$ \\
\hline $1^{e}$ & None & 0 & 0 \\
$2^{e}$ & $0.1 \mathrm{M} \mathrm{NaCl}+$ & 0 & 5 \\
& $0.01 \mathrm{TBACl}$ & $0.5 \mathrm{mM}$ & 218 \\
$3^{e}$ & None & 336 \\
$4^{e}$ & $0.01 \mathrm{M} \mathrm{NaCl}+$ & $0.5 \mathrm{mM}$ & \\
$5^{f}$ (powder) & $\begin{array}{l}0.01 \mathrm{M} \mathrm{TBACl} \\
0.1 \mathrm{M} \mathrm{NaCl}+\end{array}$ & $0.5 \mathrm{mM}$ & 0 \\
& $0.01 \mathrm{TBACl}$ & &
\end{tabular}

${ }^{a}$ Details of the photoreactor and GC detection in ESI-6, ESI. ${ }^{b} 30 \mathrm{mg}$ $\mathrm{BiVO}_{4}$ was dispersed in $35 \mathrm{~mL}$ water. ${ }^{c} 35 \mathrm{~mL}$ organic phase contained $0.05 \mathrm{M} \mathrm{TBAPF}_{6} .{ }^{d}$ Per gram of catalyst. ${ }^{e}$ Hyperbranched $\mathrm{BiVO}_{4} .{ }^{f}$ Powdered catalyst synthesized by the sol-gel method. ${ }^{41,42}$

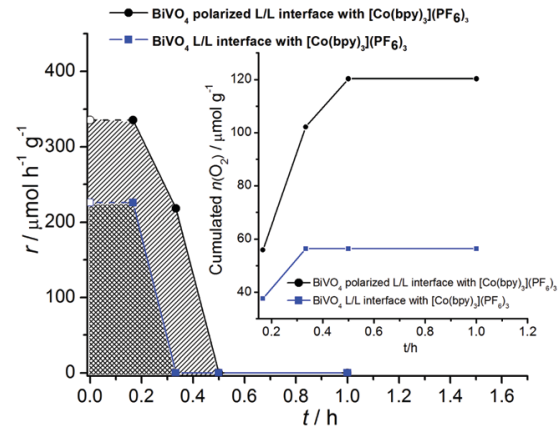

Fig. 4 Oxygen evolution rate over the reaction time. The inset figure is the cumulated amount of generated $\mathrm{O}_{2}$ assuming a linear change of $\mathrm{O}_{2}$ concentration in the exhaust gas stream between the sampling. The initial oxygen production rate at $t=0$ is assumed to be the same as that at the first sampling after $10 \mathrm{~min}$; (O) hyperbranched $\mathrm{BiVO}_{4}, 0.01 \mathrm{M} \mathrm{TBACl}$ aqueous phase, $0.5 \mathrm{mM}\left[\mathrm{Co}(\mathrm{bpy})_{3}\right]\left(\mathrm{PF}_{6}\right)_{3}+0.05 \mathrm{M} \mathrm{TBAPF}_{6}$, (ם) hyperbranched $\mathrm{BiVO}_{4}$, aqueous phase without $\mathrm{TBACl}, 0.5 \mathrm{mM}\left[\mathrm{Co}(\mathrm{bpy})_{3}\right]\left(\mathrm{PF}_{6}\right)_{3}+$ $0.05 \mathrm{M} \mathrm{TBAPF}_{6}$.

driving force due to the polarization of the ITIES by a common ion increases the $\mathrm{O}_{2}$ evolution rate.

The removal of the electrons from the $\mathrm{BiVO}_{4}$ nanostructures inhibits the otherwise fast recombination of electron-hole pairs. This requires nanostructured $\mathrm{BiVO}_{4}$ for efficient transport of electrons to the solid-liquid interface. When using the same mass of powdered $\mathrm{BiVO}_{4}$ without hyperbranched structures, the $\mathrm{O}_{2}$ evolution rate is below the detection limit. So far, many strategies have been developed to increase the efficiency of visible light-driven oxygen evolution at $\mathrm{BiVO}_{4}$ semiconductor materials applied as photocatalyst powders ${ }^{32-39}$ or modified solid electrodes ${ }^{16,17}$ in aqueous solutions with electron acceptors such as $\mathrm{Co}^{32}$ or $\mathrm{Fe}^{34,40}$ complexes, morphology control ${ }^{33}$ and facet engineering ${ }^{35}$ of $\mathrm{BiVO}_{4}$-based materials. Here, the extremely high rate of visible light-driven $\mathrm{O}_{2}$ evolution allows detection within only $10 \mathrm{~min}$ of illumination of the hyperbranched photocatalyst powder by separation of photo-induced charge carriers at a molecular interface. A similar value of $238 \mu \mathrm{mol} \mathrm{h} \mathrm{h}^{-1} \mathrm{~g}^{-1}$ is also obtained with $\mathrm{Ag}^{+}$as a scavenger in the first $15 \mathrm{~min}$ of operation and with a larger optical band $(\lambda>320 \mathrm{~nm})$.

The very high initial activity decreased within $20-30 \mathrm{~min}$ to levels below the detection limit of our system $\left(c a .1 \mu \mathrm{mol} \mathrm{h}{ }^{-1}\right)$. The data are shown in Fig. 4. The accumulated amounts of $\mathrm{O}_{2}$ generated during the reaction time are plotted in Fig. 4. They compare favourably to amounts of $\mathrm{O}_{2}$ detected within 1-5 hours for $\mathrm{BiVO}_{4}$ systems as reported recently. ${ }^{32-39}$

In conclusion, a completely new approach has been proposed by which the photochemical behavior of $\mathrm{BiVO}_{4}$ semiconductor nanostructures can be improved for visible light-driven oxidation of water. The nanoparticulate $\mathrm{BiVO}_{4}$ semiconductor is assembled at the water/butyronitrile interface polarized by the common, highly hydrophobic tetraalkylammonium cation partitioning between the two liquid phases. A $\mathrm{Co}^{\mathrm{III}}$ complex acts as an electron acceptor in the organic phase. The high surface area of nanosized $\mathrm{BiVO}_{4}$ crystals with a specific hyperbranched structure along with the defect free ITIES minimizes the interfacial recombination of photo-excited electron-hole pairs by 
rapidly transferring electrons to reactants in the adjacent liquid phases. The ET reaction can be characterized sensitively by oxidation of $\left[\mathrm{Co}(\mathrm{bpy})_{3}\right]^{2+}$ originating from the photo-driven reaction at the ITIES using a SECM configuration in the organic phase.

Moreover, the driving force for the photo-induced ET reaction could be readily maximized by chemically controlling the polarization of the interface. This improves the WOR compared to recent reports on WOR using powdered $\mathrm{BiVO}_{4}$ photocatalysts. It is expected that the new strategy developed in this work will promote efficient water splitting with powdered $\mathrm{BiVO}_{4}$ photocatalysts in large-scale solar-to-hydrogen conversion. Further studies will be directed to address details of WOR mechanisms at $\mathrm{BiVO}_{4}$ at ITIES, integrating other approaches such as doping of $\mathrm{BiVO}_{4}$.

We are grateful to Prof. Dr Michael Wark and Sven Warfsmann (Institute of Chemistry, Carl von University of Oldenburg) for help with measuring $\mathrm{O}_{2}$ evolution rates. S. R. thanks the Hanse Institute of Advanced Studies Delmenhorst and the Alexander von Humboldt Foundation for research fellowships.

\section{Notes and references}

1 M. K. Dymond, C. V. Hague, A. D. Postle and G. S. Attard, J. R. Soc., Interface, 2013, 10, 1.

2 D. Gust, T. A. Moore and A. L. Moore, Acc. Chem. Res., 2009, 42, 1890.

3 M. G. Walter, E. L. Warren, J. R. McKone, S. W. Boettcher, Q. Mi, E. A. Santori and N. S. Lewis, Chem. Rev., 2010, 110, 6446.

4 M. D. Kärkäs, O. Verho, E. V. Johnston and B. r. Åkermark, Chem. Rev., 2014, 114, 11863.

5 D. R. Weinberg, C. J. Gagliardi, J. F. Hull, C. F. Murphy, C. A. Kent, B. C. Westlake, A. Paul, D. H. Ess, D. G. McCafferty and T. J. Meyer, Chem. Rev., 2012, 112, 4016.

6 R. Lahtinen, D. J. Fermin, K. Kontturi and H. H. Girault, J. Electroanal. Chem., 2000, 483, 81.

7 N. Eugster, D. J. Fermín and H. H. Girault, J. Phys. Chem. B, 2002, 106, 3428.

8 N. Eugster, D. J. Fermín and H. H. Girault, J. Am. Chem. Soc., 2003, 125, 4862.

9 H. Nagatani, S. Dejima, H. Hotta, T. Ozeki and T. Osakai, Anal. Sci., 2004, 20, 1575.

10 J. K. Cooper and I. Benjamin, J. Phys. Chem. B, 2014, 118, 7703.

11 D. Schaming, I. Hatay, F. Cortez, A. Olaya, M. A. Méndez, P. Y. Ge, H. Deng, P. Voyame, Z. Nazemi and H. Girault, Chimia, 2011, 65, 356.
12 H. Inoue, T. Shimada, Y. Kou, Y. Nabetani, D. Masui, S. Takagi and H. Tachibana, ChemSusChem, 2011, 4, 173.

13 A. Kudo, K. Omori and H. Kato, J. Am. Chem. Soc., 1999, 121, 11459. 14 J. Gan, X. Lu and Y. Tong, Nanoscale, 2014, 6, 7142.

15 Z.-F. Huang, L. Pan, J.-J. Zou, X. Zhang and L. Wang, Nanoscale, 2014, 6, 14044.

16 Y. Park, K. J. McDonald and K.-S. Choi, Chem. Soc. Rev., 2013, 42, 2321.

17 T. Hisatomi, J. Kubota and K. Domen, Chem. Soc. Rev., 2014, 43, 7520.

18 A. G. Volkov, D. W. Deamer, D. L. Tanelian and V. S. Markin, Liquid Interfaces in Chemistry and Biology, J Wiley, New York, 1998.

19 F. Li, B. Su, F. C. Salazar, R. P. Nia and H. H. Girault, Electrochem. Commun., 2009, 11, 473.

20 P. Sun, F. Li, Y. Chen, M. Zhang, Z. Zhang, Z. Gao and Y. Shao, J. Am. Chem. Soc., 2003, 125, 9600.

21 Z. Ding, B. M. Quinn and A. J. Bard, J. Phys. Chem. B, 2001, 105, 6367.

22 F. Li and P. R. Unwin, J. Phys. Chem. C, 2015, 119, 4031.

23 R. Ishimatsu, J. Kim, P. Jing, C. C. Striemer, D. Z. Fang, P. M. Fauchet, J. L. McGrath and S. Amemiya, Anal. Chem., 2010, 82, 7127.

24 X. Lu, T. Wang, X. Zhou, Y. Li, B. Wu and X. Liu, J. Phys. Chem. C, 2011, 115, 4800.

25 Y. Wang, K. Kececi, J. Velmurugan and M. V. Mirkin, J. Chem. Sci., 2013, 4, 3606.

26 S. Amemiya and A. J. Bard, Anal. Chem., 2000, 72, 4940.

27 J. Strutwolf, J. Zhang, A. L. Barker and P. R. Unwin, Phys. Chem. Chem. Phys., 2001, 3, 5553.

28 W. Adamiak, J. Jedraszko, O. Krysiak, W. Nogala, J. C. Hidalgo-Acosta, H. H. Girault and M. Opallo, J. Phys. Chem. C, 2014, 118, 23154.

29 S. J. Hong, S. Lee, J. S. Jang and J. S. Lee, Energy Environ. Sci., 2011, 4, 1781.

30 M. Tsionsky, A. J. Bard and M. V. Mirkin, J. Phys. Chem. C, 1996, 100, 17881.

31 H. Jensen, D. J. Fermín, J. E. Moser and H. H. Girault, J. Phys. Chem. $B, 2002,106,10908$.

32 Y. Sasaki, H. Kato and A. Kudo, J. Am. Chem. Soc., 2013, 135, 5441.

33 Y. Zhao, Y. Xie, X. Zhu, S. Yan and S. Wang, Chem. - Eur. J., 2008, 14, 1601.

34 D. J. Martin, P. J. T. Reardon, S. J. A. Moniz and J. Tang, J. Am. Chem. Soc., 2014, 136, 12568.

35 D. Wang, H. Jiang, X. Zong, Q. Xu, Y. Ma, G. Li and C. Li, Chem. Eur. J., 2011, 17, 1275.

36 P. Zhou, J. Yu and M. Jaroniec, Adv. Mater., 2014, 26, 4920.

37 A. Iwase, Y. H. Ng, Y. Ishiguro, A. Kudo and R. Amal, J. Am. Chem. Soc., 2011, 133, 11054.

38 Y. Sasaki, H. Nemoto, K. Saito and A. Kudo, J. Phys. Chem. C, 2009, $113,17536$.

39 Q. Jia, A. Iwase and A. Kudo, J. Chem. Sci., 2014, 5, 1513.

40 M. T. McDowell, M. F. Lichterman, J. M. Spurgeon, S. Hu, I. D. Sharp, B. S. Brunschwig and N. S. Lewis, J. Phys. Chem. C, 2014, 118, 19618.

41 P. Pookmanee, S. Kojinok and S. Phanichphant, J. Met., Mater. Miner., 2012, 22, 49.

42 O. Merka, O. Raisch, F. Steinbach, D. W. Bahnemann and M. Wark, J. Am. Ceram. Soc., 2013, 96, 634. 